\title{
Effect of Different Doses of Acute Gamma Radiation on the Cultivation of Volvariella volvacea
}

\author{
Fatin Nabilah Fisol', Sumaiyah Abdullah ${ }^{1 *}$, Azhar Mohamad², Mahmud Tengku Muda Mohamed ${ }^{1}$, Azizah Misran', \\ Sabiha Salim ${ }^{3}$ and Badrul Azhar ${ }^{3}$ \\ ${ }^{1}$ Faculty of Agriculture, Universiti Putra Malaysia, 43400 Serdang, Selangor, Malaysia \\ ${ }^{2}$ Malaysian Nuclear Agency, Bangi, 43000 Kajang, Selangor, Malaysia \\ ${ }^{3}$ Faculty of Forestry and Environment, Universiti Putra Malaysia, 43400 Serdang, Selangor, Malaysia \\ *For correspondence: sumaiyah@upm.edu.my \\ Received 30 September 2021; Accepted 26 November; Published 30 January 2022
}

\begin{abstract}
In mushroom cultivation, acute gamma radiation can be used and studied to improve the production of its fruiting body. Therefore, the objective of this study was to investigate the effect of gamma radiation on the mycelial growth and production of the fruiting body of Volvariella volvacea (Bull.) Singer. The mycelia were exposed to gamma radiation at various doses: 0 (control), 300, 600, 900, 1200 and $1500 \mathrm{~Gy}$. The irradiated mycelial growth rate was recorded on potato dextrose agar (PDA) and spawning substrate. The spawn was then produced by inoculating the treated mycelia on paddy straw and subsequently cultivated on an empty fruit bunch to compare the production. The result showed no significant difference in mycelial growth rate on wheat, the number of mushrooms, and mushroom weight between control and treatments of 300 , 600 and $900 \mathrm{~Gy}$. However, there was the presence of hairy structures on the fruiting bodies of $V$. volvacea in all spawns with irradiated mycelia and the production of clustered fruiting bodies from spawns treated with $1200 \mathrm{~Gy}$ observed. The effect of treatments on the texture of fruiting bodies was insignificant. Although acute gamma radiation did not significantly increase the production of $V$. volvacea compared to the control treatment, there were morphological changes observed on the V. volvacea fruiting body which can be studied further. (C) 2022 Friends Science Publishers
\end{abstract}

Keywords: Gamma radiation; Irradiation; Mycelium; Oil palm empty fruit bunch; Spawn

\section{Introduction}

Volvariella volvacea (Bull.) Singer belongs to the Volvariella genus from the Pluteacea family, is an edible cultivated mushroom and commonly known as paddy straw mushroom or Chinese mushroom (Chang 1977; Chen et al. 2019). Volvariella volvacea is widely grown in tropical and subtropical climates like China, Thailand, Philippines, and Malaysia (Bao et al. 2013). Due to $V$. volvacea qualities of having a nice texture and aroma, pleasant flavour, fast growth rate, and easy cultivation technology, this mushroom became a popular choice amongst consumers and growers (Ahlawat and Tewari 2007; Thiribhuvanamala et al. 2012; He et al. 2018). Besides that, the demand and cultivation practices of $V$. volvacea have increased worldwide, given their rich protein content of 19 to $35 \%$ of protein on a dry weight basis with all essential amino acids required by the human body (Kumud et al. 2014). Furthermore, Volvariella volvacea additionally has significant pharmaceutical values, such as immunosuppressive proteins, anti-tumor polysaccharides, and immunomodulatory lectins (Liu et al. 2011). Therefore, the cultivation of $V$. volvacea in Malaysia could promote societal livelihood through economic, nutritional, and medicinal values (Marshall and Nair 2009; Rosmiza et al. 2016).

The cultivation of $V$. volvacea is increasingly popular worldwide because of factors like prevailing external climatic conditions, short growing times, low input requirements, and since agricultural waste is highly available, only a small investment is needed (Ahlawat and Tewari 2007; Rosmiza et al. 2016). There are several factors that affect the growth and production of $V$. volvacea, such as spawn production, a substrate for the mushroom bed, and conditions during cultivation like temperature, relative humidity, and hydrogen potential (Miles and Chang 2004). Moreover, Ukoima et al. (2009) stated that using an empty fruit bunch (EFB) as the substrate could increase the production of $V$. volvacea and reduce biomass waste in the environment. The highest possible production of $V$. volvacea is obtainable through high-quality mycelium and substrate in the spawn preparation. Therefore, improving the quality of the mycelium enhances the quality of the spawn, which in turn might result in high production of the mushroom.

To cite this paper: Fisol FN, S Abdullah, A Mohamad, MTM Mohamed, A Misran, S Salim, B Azhar (2022). Effect of different doses of acute gamma radiation on the cultivation of Volvariella volvacea (Bull.) singer. Intl J Agric Biol 27:53-59 
In recent studies, the application of mutation techniques using acute gamma radiation on the mycelium was suggested to improve mushroom production by developing new varieties of mushroom species (Rashid et al. 2014). Irradiation refers to a process of exposing a substance to ionizing radiation from a variety of different sources, such as electron beams and gamma rays (Akram and Kwon 2010; Fernandes et al. 2012). Gamma rays have been reported as an efficient ionizing radiation technique and one of the most convenient methods in performing radiation-induced mutation for developing new varieties as it can cause mutation over a wide spectrum (Nakagawa 2009; Noordin et al. 2014). Whether spontaneous or induced, the mutations are crucial for genetic variability, which can improve crop yield (Manjaya 2009). Furthermore, Ibrahim et al. (2017) showed the exposure of gamma irradiation on the mycelium of $L$. edodes, proving that irradiation can affect the mycelial growth of the mushroom due to the alteration of the genetic compatibility of these mycelia. In addition, gamma irradiation is usually applied as an improved post-harvest technology on fresh mushrooms (Akram et al. 2012). However, there were no reported trials on acute gamma radiation used to the mycelia of $V$. volvacea during the spawn preparation. Therefore, this study aimed to determine the optimal doses of radiation exposure for improving the growth and production of $V$. volvacea.

\section{Materials and Methods}

\section{Irradiation treatment}

The PDA culture of $V$. volvacea with complete mycelial inoculation was irradiated using Biobeam GM 8000 Gamma Irradiator with Cesium-137 (Cs-137) as radioactive sources. Mycelia samples were exposed at six different low doses of irradiation, i.e., 0 (control), 300, 600, 900, 1200 and $1500 \mathrm{~Gy}$ at a rate of $12.5 \mathrm{~Gy} \mathrm{~min}^{-1}$. Each treatment contained three samples of irradiated mycelia. The irradiated mycelia for each treatment were sub-cultured on the new PDA. All the subcultures were next incubated at room temperature, RT (25 $\pm 2{ }^{\circ} \mathrm{C}$ ). The growth of mycelium on PDA was measured by drawing two perpendiculars of a straight line at the back of each Petri dish. The measurement unit used was in millimetres $(\mathrm{mm})$. The mycelial growth on PDA was recorded every day for seven days. The growth rates were determined by fitting the linear growth function, following the formula of $y=k_{r} X+c$ (where, $k_{r}$ is the growth rate, $y$ is the distance covered by mycelium, and $\mathrm{x}$ is the respective time) and expressed in $\mathrm{mm} \mathrm{day}^{-1}$ (Koutrotsios and Zervakis 2014).

\section{Inoculation of irradiated mycelia on wheat}

The selected mycelia grown from each treatment were inoculated on a wheat substrate prepared in test tubes with dimensions of $60 \times 25 \mathrm{~mm}$. The samples were incubated at room temperature, RT $\left(25 \pm 2^{\circ} \mathrm{C}\right)$. The growth of mycelium along the test tubes was observed at two-day intervals, with the growth rate of mycelium being determined. Moreover, the growth of mycelium on the wheat substrate was recorded by measuring the mycelia running down along the test tube. The growth of mycelia was observed and recorded in two-day intervals, and the growth rate was determined.

\section{Preparation of spawn and mushroom bed}

Spawn's preparation: The method of preparation of the spawn followed Miles and Chang (2004) with a slight modification. First of all, the paddy straw was soaked in water for about four hours. The paddy straw was then washed and left to remove excess water. After that, the paddy straw was cut into a shorter length $(5-7 \mathrm{~cm})$. Subsequently, it was mixed with $1 \%$ calcium carbonate, $\mathrm{CaCO}_{3}$. Then, the paddy straw was transferred into a polypropylene plastic bag and covered with a cap. Each treatment consists of four replicates with $100 \mathrm{~g}$ of paddy straw for each bag. The prepared spawn bags were autoclaved at $121^{\circ} \mathrm{C}$ for $60 \mathrm{~min}$ and left to cool at room temperature $\left(25 \pm 2{ }^{\circ} \mathrm{C}\right)$. About 10 to 15 grains covered with mycelium from each irradiation dose were transferred into the prepared spawn bag. This process was done under a sterilized condition. The inoculated spawn bags were left at room temperature $\left(25 \pm 2^{\circ} \mathrm{C}\right)$ until the spawn run for each treatment was completed.

Mushroom bed preparation: The empty fruit bunch (EFB) was prepared and used as the substrate for the mushroom bed. The EFB was composted for nine days, covered by canvas, and watered at three-day intervals. The $\mathrm{pH}$ of the EFB was adjusted using calcium carbonate, $\mathrm{CaCO}_{3}$ to achieve $\mathrm{pH} 6-8$. After nine days, the EFB was watered until reaching 70-80\% moisture and was feet-pressed to remove excess water and reduce the air gap in the bed to ensure more compact mycelial growth. The EFB was then arranged in a basket with a measurement of $45 \times 35 \mathrm{~cm}$. Hundreds of grams of treated spawn from each treatment were used for one mushroom bed. There were four replicates of mushroom beds for each treatment. All the mushroom beds were covered with black polythene sheets for seven days. After seven days, the polythene cover was removed to prepare the polypipe into a dome shape before the polythene sheet was lifted using polypipe as the support.

\section{Determination of $V$. volvacea production and texture analysis}

Production of the fruiting body: After 15 days from the spawning process, the first flush of $V$. volvacea was observed and harvested. The mushrooms were harvested at the button stage. The numbers and weight of the mushrooms for each treatment were recorded for each harvest time or flush.

Texture analysis: Five replicates of the button stage of $V$. volvacea weighing in the range of $25 \pm 2 \mathrm{~g}$ from each treatment were chosen. The texture analysis was done using an 
Instron Texture Analyzer to compare the firmness of the mushroom.

\section{Statistical analysis}

The raw data were processed using Microsoft Excel 2016, and all the statistical tests included Analysis of Variance (ANOVA), and Duncan Multiple Range Test, which is for multiple mean comparisons, were performed using Statistical Analysis System (SAS) 9.4 Software.

\section{Results}

\section{Growth of $V$. volvacea mycelia on PDA and wheat grains}

Mycelia growth on PDA: All treatments showed thick white cottony mycelia before light orange formation began to appear as early as day 6 . The time taken for spawn run for mycelia irradiated with 1500 Gy was longer, reaching nine days compared to other treatments, which were only seven days. Besides that, there was no noticeable difference in mycelia colour and growth characteristic between all treatments (Fig. 1). However, the treatments of 600 and 900 Gy resulted in significantly higher growth rates of $V$. volvacea mycelia, which are $11.78 \pm 0.10 \mathrm{~mm} \mathrm{day}^{-1}$ and $11.85 \pm 0.13 \mathrm{~mm}$ day $^{-1}$, respectively to control $(10.72 \pm 0.16$ $\mathrm{mm}$ /day) and other treatments (Fig. 2).

Mycelia growth on wheat: There was no significant difference $(P>0.05)$ in the mean growth rate of mycelia irradiated with 300,600 and 900 Gy $(9.57 \pm 0.20,9.82 \pm$ 0.16 , and $9.83 \pm 0.17 \mathrm{~mm} \mathrm{day}^{-1}$, respectively) compared to 0 Gy which at $9.70 \pm 0.16 \mathrm{~mm} \mathrm{day}^{-1}$ (Fig. 3). Even though the mycelia irradiated with 1200 and 1500 Gy had slower growth rates $\left(8.62 \pm 0.20\right.$ and $8.23 \pm 0.09 \mathrm{~mm} \mathrm{day}^{-1}$, respectively), there were no noticeable in the colour of mycelia and no mortality of mycelia observed (Fig. 4).

\section{Evaluation of $\boldsymbol{V}$. volvacea production for each treatment}

Harvesting periods: The cultivation period is the time between the spawning and production of the first flush of mushrooms. The spawn with mycelium irradiated at 1500 Gy took the longest time to produce a fruiting body compared to other treatments. The spawn with 300, 600 and 900 Gy irradiated mycelia showed a shorter time for fruiting body production compared to control and spawn with 1200 Gy irradiated mycelia (Table 1).

Physical appearance: This study resulted in no noticeable differences in the colour appearance of the fruiting body of $V$. volvacea produced between all treatments. However, there was a noticeable presence of hairy structure on the fruiting body produced by all spawn with irradiated mycelia (Table 1). In addition, the fruiting body produced from spawn treated with 1200 Gy irradiated mycelia showed a clustered form.

Number and weight of fruiting body: The mean number of mushrooms produced by 300, 600 and 900 Gy showed no significant difference $(P>0.05)$ to control except for treatments 1200 and 1500 Gy (Table 2). The mean weight of the fruiting body showed no significant difference between control treatment and spawned treated with 300 , 600, 900 and 1200 Gy. However, spawn with 1500 Gy irradiated mycelia showed very poor production of $V$. volvacea, with only one out of four replicates of the mushroom bed producing $V$. volvacea fruiting body. The other beds of 1500 Gy spawn showed stunted growth of fruiting bodies, which only grows until the pinhead stage.

The texture of fruiting body: The mean texture (firmness) of the fruiting body of $V$. volvacea showed no significant difference $(P>0.05)$ between all treatments (Table 2$)$.

\section{Discussion}

Results obtained from this study suggested that the mycelial growth rate of $V$. volvacea on PDA and wheat was significantly affected by gamma irradiation. The growth rate of $V$. volvacea mycelia increased from control (0 Gy) until 900 Gy before it started showing a decreasing mycelial growth on PDA. On the other hand, on the wheat substrate, the mycelia irradiated with 1200 and 1500 Gy showed a significantly slower growth rate compared to others. The growth rate of a mycelium depends on the formation of clamps, which enables the exchange of genes and extension to more areas as compatible mated mycelia was observed, showing a faster growth (Kothe 2001; Rosnina et al. 2016). Ibrahim et al. (2017) study on Lentinula edodes that were exposed to a higher dose of gamma irradiation showed decreasing numbers of clamp connections compared to control. The study indicates that there are genetic compatibility changes between individual hyphal cells within the irradiated L. edodes mycelia. In short, exposure to higher doses of gamma radiation could decrease the number of clamps, thus reducing mycelial growth. This also caused the possibility of sterile mycelia being selected during the subculture process to increase.

Moreover, Beejan and Nowbuth (2009) studied the gamma irradiation on a different strain of Pleurotus species resulted in no definitive trend alterations observed in mycelia colonization rates on media with the increasing doses of gamma radiation. They concluded that irradiation could improve the Pleurotus spp. strains, and at certain strains under different doses, the mushroom yield can be enhanced. Therefore, the mycelial growth on the PDA and substrate can be different depending on the mushroom species and types of substrate used.

The clustered fruiting body of $V$. volvacea at the button stage is perhaps induced by gamma-ray mutagenesis. According to Nie et al. (2017), all the abnormalities in the morphology of $V$. volvacea produced compared to control can indicate mutation. The gamma radiation could modify some physiological characteristics and thus create new mutants. This could help produce higher amounts of 
Fisol et al. / Intl J Agric Biol, Vol 27, No 1, 2022

Table 1: The evaluation of $V$. volvacea characteristics produced from each treatment

\begin{tabular}{|c|c|c|}
\hline Dose (Gy) & Cultivation period (Four replicates of mushroom's bed) & Characteristic of the fruiting body at button stage \\
\hline 0 (control) & 18 days & $\begin{array}{l}\text { i) White colour } \\
\text { ii) No hairy structure presence }\end{array}$ \\
\hline 300 & 15 days & $\begin{array}{l}\text { i) White colour } \\
\text { ii) Presence of hairy structure at the base of the fruiting body }\end{array}$ \\
\hline 600 & 15 days & $\begin{array}{l}\text { i) White colour } \\
\text { ii) Presence of hairy structure at the base and the surface of fruiting body }\end{array}$ \\
\hline 900 & 15 days & $\begin{array}{l}\text { i) White colour } \\
\text { ii) Presence of hairy structure at the base and the surface of fruiting body }\end{array}$ \\
\hline 1200 & 18 days & $\begin{array}{l}\text { i) White colour } \\
\text { ii) Presence of hairy structure at the base and the surface of fruiting body } \\
\text { iii) Most fruiting bodies produced in clustered form }\end{array}$ \\
\hline 1500 & 24 days (only one mushroom's bed produce the fruiting body) & $\begin{array}{l}\text { i) White colour } \\
\text { ii) Presence of hairy structure at the base and the surface of fruiting body }\end{array}$ \\
\hline
\end{tabular}

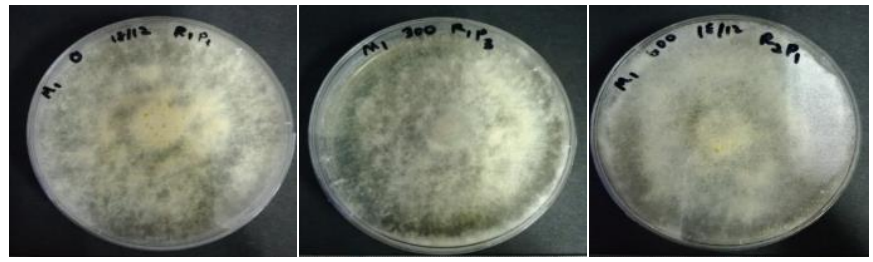

(a)

(b)

(c)

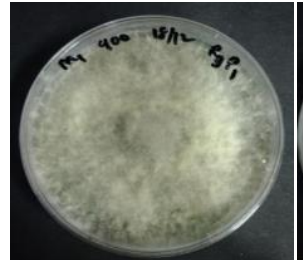

(d)

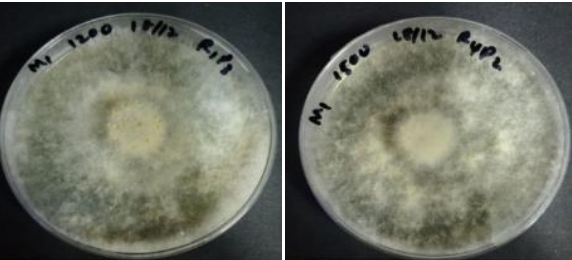

(e) (f)

Fig. 1: The mycelial growth on PDA at day 7 for each irradiation doses; (a) 0, (b) 300, (c) 600, (d) 900, (e) 1200 and (f) 1500 Gy

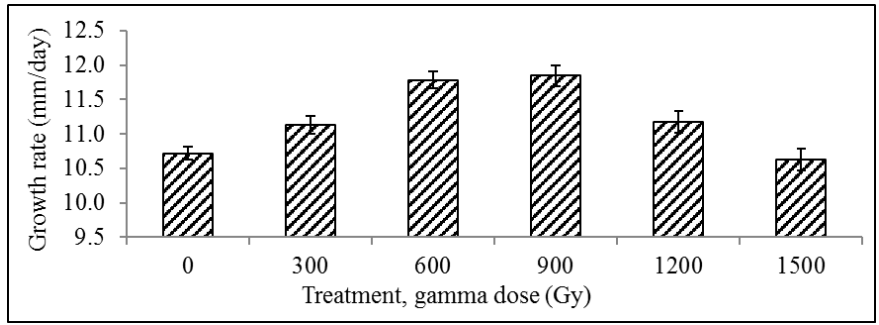

Fig. 2: The mean growth rate of mycelia $(\mathrm{mm} /$ day \pm S.E) on PDA for each dose of irradiation throughout seven days

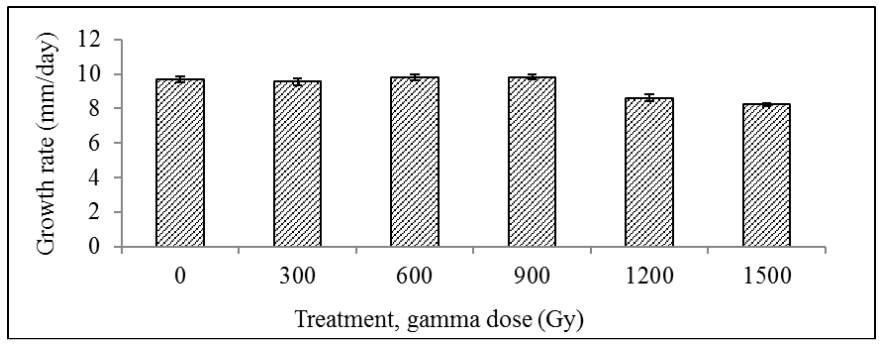

Fig. 3: The growth rate of mycelia $(\mathrm{mm} /$ day \pm S.E) on wheat for each dose of irradiation for 12 days

essential metabolites, developing agriculturally and economically significant varieties besides potentially increasing productivity (Noordin et al. 2014). In this study, only spawn colonized with 1500 Gy irradiated mycelia showed very poor production, while other treatments showed no significant difference to control treatment. 
Table 2: Mean number, weight (g), and texture of fruiting body for each treatment

\begin{tabular}{llll}
\hline Treatment (Gy) & Number \pm SE & Weight \pm SE $(\mathrm{g})$ & Texture \pm SE $(\mathrm{N})$ \\
\hline 0 & $6.00 \pm 1.22^{\mathrm{a}}$ & $105.38 \pm 26.82^{\mathrm{ab}}$ & $13.75 \pm 0.55^{\mathrm{a}}$ \\
300 & $6.75 \pm 1.25^{\mathrm{a}}$ & $104.00 \pm 22.58^{\mathrm{ab}}$ & $13.04 \pm 0.22^{\mathrm{a}}$ \\
600 & $7.75 \pm 1.31^{\mathrm{a}}$ & $140.25 \pm 21.43^{\mathrm{a}}$ & $12.41 \pm 0.10^{\mathrm{a}}$ \\
900 & $8.00 \pm 0.58^{\mathrm{a}}$ & $162.88 \pm 10.54^{\mathrm{a}}$ & $12.25 \pm 0.33^{\mathrm{a}}$ \\
1200 & $2.75 \pm 0.48^{\mathrm{b}}$ & $43.88 \pm 16.81^{\mathrm{bc}}$ & $12.48 \pm 0.84^{\mathrm{a}}$ \\
1500 & $0.25 \pm 0.25^{\mathrm{b}}$ & $2.50 \pm 2.50^{\mathrm{c}}$ & $\mathrm{Nd}$ \\
\hline
\end{tabular}

$\mathrm{Nd}$ is not determined. The same superscript letter for each value in the same column showed no significant difference $(P>0.05)$ between the treatments

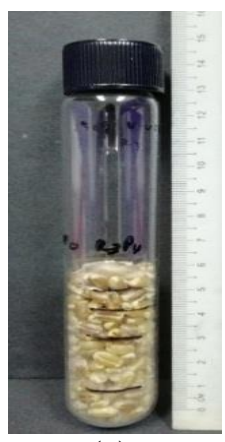

(a)

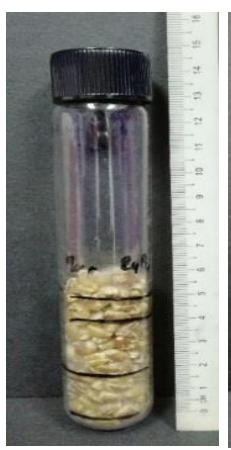

(d)

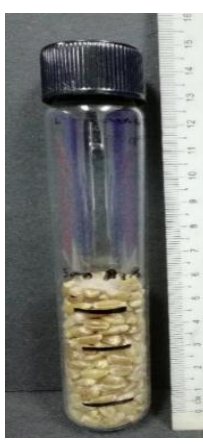

(b)

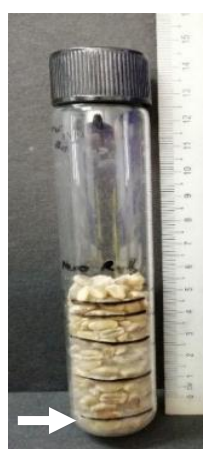

(e)

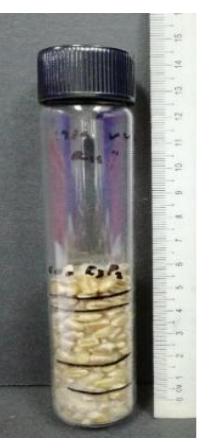

(c)

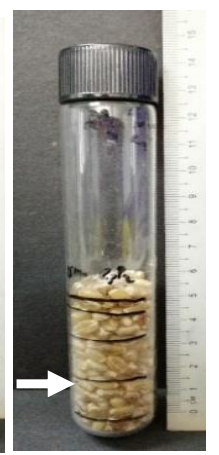

(f)

Fig. 4: The mycelial growth on wheat at Day 12 for each irradiation dose; (a) 0, (b) 300, (c) 600, (d) 900, (e) 1200 and (f) 1500 Gy. The mycelia completely covered the wheat at Day 12 for treatments 0, 300, 600 and 900 Gy. The mycelial growth of treatments 1200 and 1500 Gy at Day 12 showed the arrow in Fig. 4 (e) and (f)

Therefore, any increase in the induction of gamma radiation on mycelium more than 1500 Gy possibly shows no mushroom production. Apart from that, Lee et al. (2000) investigated the gamma irradiation exposure on $P$. ostreatus mycelia at $2000 \mathrm{~Gy}$, which showed a reduction in mycelial growth compared to mycelia irradiated at $1000 \mathrm{~Gy}$. However, the study concluded that the mycelia irradiated at $2000 \mathrm{~Gy}$ also able to produce a fruiting body.

Besides, Ramchander et al. (2015) stated that the nature of mutation could be decided by determining the correct radiation doses. Therefore, a mutation can happen to the mycelial strain at certain radiation doses, causing no production of fruiting bodies of $V$. volvacea. The texture analysis of a mushroom indicates that the mushroom has high firmness. However, this study concluded that acute gamma irradiation does not affect the firmness of the fruiting body. Other than that, Shrivastava (2006) also showed a similar result for oyster mushrooms where there was no significant difference in the texture of mushrooms between all treatments during storage. However, Hou et al. (2018) indicate that gamma irradiation $(0.8 \mathrm{kGy})$ on the fruiting body of $V$. volvacea helps in maintaining their good quality and firmness for seven days storage period under $16 \pm 0.5^{\circ} \mathrm{C}$ compared to other irradiation doses. Another study was done by Xiong et al. (2009) on gamma irradiation of Pleurotus nebrodensis at 1200 and 2000 Gy, which reduced fruiting bodies firmness by 45 and $62 \%$, respectively. Meanwhile, the reduction percentage of the fruiting body firmness control group (non-irradiated) was $58 \%$. Although the study on gamma irradiation showed a significant effect on the mushroom morphology, the IAEA (1992) reported that irradiation with an average dose of 
10000 Gy shows no toxicological hazards and introduces no specific microbial or nutritional problems. Therefore, the irradiation method can be implemented in mushroom production for commercial purposes.

\section{Conclusion}

Acute gamma radiation on mycelia showed a significant effect on the spawning rate of $V$. volvacea. Further study on the effect of acute gamma radiation on nutrient content and physiological changes in fruiting bodies of $V$. volvacea is highly recommended. It is hoped that this study will stimulate improvement in current mushroom cultivation methods, thereby contributing to the production and quality of the $V$. volvacea simultaneously.

\section{Acknowledgments}

All the work was carried out by facilities provided at the Faculty of Agriculture, Universiti Putra Malaysia and Malaysian Nuclear Agency. This work was supported by Malaysian Higher Education (MOHE) for the FRGS grants (FRGS/1/2016/WAB01/UPM/02/15. We are thankful to Mohamad Yuzaidi Azmi from the Department of Agriculture (DOA) Padang Terap, Kedah, for his willingness to participate in this study.

\section{Author's Contributions}

FNF performed the methodology, collected and analyzed the result. Also, FNF wrote the manuscript. SA, AM, designed the conceptual ideas and interpreted the results. SA, SS and BA participated and revised the manuscript. Apart from that, SA, MTMM, AM participated and supervised the project. All authors have read and agreed to the published version of the manuscript.

\section{Conflicts of Interest}

All authors declare no conflicts of interest.

\section{Data Availability}

Data presented in this study will be available on a fair request to the corresponding author.

\section{Ethics Approval}

Not applicable.

\section{References}

Ahlawat OP, RP Tewari (2007). Cultivation Technology of Paddy Straw Mushroom (Volvariella volvacea). National Research Centre for Mushroom, Indian Council of Agricultural Research, New Delhi, India
Akram K, JH Kwon (2010). Food irradiation for mushrooms: A review. J Kor Soc Appl Biol Chem 53:257-265

Akram K, JJ Ahn, SR Yoon, GR Kim, JH Kwon (2012). Quality attributes of Pleurotus eryngii following gamma irradiation. Postharv Biol Technol 66:42-47

Bao D, M Gong, H Zheng, M Chen, L Zhang, H Wang, J Jiang, L Wu, Y Zhu, G Zhu, Y Zhou, C Li, S Wang, Y Zhou, G Zhao, Q Tan (2013). Sequencing and comparative analysis of the straw mushroom (Volvariella volvacea) genome. PLoS One 8:1-12

Beejan PHF, R Nowbuth (2009). Use of irradiation for the induction of mutations in oyster mushrooms for improvement of strains. In: Induced plant mutations in the genomics era, pp:289-293. Shu QY (Ed). Joint FAO/IAEA Programme. Nuclear techniques in food and agriculture. Vienna, Austria

Chang ST (1977). The origin and early development of straw mushroom cultivation. Econ Bot 31:374-376

Chen B, G Wu, L Li, Q Wei, Q Zhong, X Chen, K Xiao, B Xie, Y Jiang (2019). Effects of 1-methylcyclopropene on the quality attributes of harvested Chinese mushroom (Volvariella volvacea) fruiting bodies. Food Sci Nutr 7:747-754

Fernandes A, AL Antonio, MBP Oliveira, A Martins, IC Ferreira (2012). Effect of gamma and electron beam irradiation on the physicochemical and nutritional properties of mushrooms: A review. Food Chem 135:641-650

He BL, LR You, ZW Ye, LQ Guo, JF Lin, T Wei, QW Zheng (2018). Construction of novel cold-tolerant strains of Volvariella volvaced through protoplast fusion between Volvariella volvacea and Pleurotus eryngii. Sci Hortic 230:161-168

Hou L, J Lin, L Ma, S Qu, H Li, N Jiang (2018). Effect of 60Co gamma irradiation on postharvest quality and selected enzyme activities of Volvariella volvacea. Sci Hortic 235:382-390

IAEA (International Atomic Energy Agency) (1992). Irradiation of spices, herbs and other vegetable seasonings. A compilation of technical data for its authorization and control. Vienna, Austria

Ibrahim M, M Azhar, D Fauzi, AK Zaiton, H Nie, HH Hisham, SWAR Wan, OB Aririanah, F Shazrul (2017). Variants production of Lentinula edodes spores, monokaryon mycelium and dikaryon mycelium by $\gamma$-irradiation. Malays Appl Biol 46:77-82

Kothe E (2001). Mating-type genes for basi-diomycete strain improvement in mushroom farming. Appl Microbiol Biotechnol 56:602-612

Koutrotsios G, GI Zervakis (2014). Comparative examination of the olive mill wastewater biodegradation process by various wood-rot macrofungi. Biomed Res Intl 2014:1-14

Kumud K, S Lily, B Behera, KB Mohapatra (2014). Improvement of biological efficiency of paddy straw on mushroom through substrate management. Environ Ecol 32:33-39

Lee YK, HH Chang, JS Kim, JK Kim, KS Lee (2000). Lignocellulolytic mutants of Pleurotus ostreatus induced by gamma-ray radiation and their genetic similarities. Radiat Phys Chem 57:145-150

Liu Z, K Zhang, JF Lin, LQ Guo (2011). Breeding cold tolerance strain by chemical mutagenesis in Volvariella volvacea. Sci Hortic 130:18-24

Manjaya JG (2009). Genetic improvement of soybean variety VLS-2 through induced mutations. Small 38:106-109

Marshall E, NG Nair (2009). Make Money by Growing Mushrooms. Food and Agriculture Organization of the United Nations (FAO)

Miles PG, ST Chang (2004). Mushrooms: Cultivation, Nutritional Value, Medicinal Effect, and Environmental Impact, CRC press, Boca Raton, Florida, USA

Nakagawa H (2009). Induced mutations in plant breeding and biological researches in Japan. Crops 242:48-54

Nie HJ, A Mohamad, ZA Kadir, WSWA Razak, I Mahmood, HH Hussain (2017). Dose response for Auricularia auricula-judaeagainst acute gamma irradiation. Malays Appl Biol 46:71-75

Noordin N, R Ibrahim, NHM Sajahan, S Moosa, S Hussein (2014). Effects of acute and chronic gamma irradiation on in vitro growth of Stevic rebaudiana Bertoni. J Malays Nucl Sci 26:17-25

Ramchander S, R Ushakumari, MA Pillai (2015). Lethal dose fixation and sensitivity of rice varieties to gamma radiation. Ind J Agric Res 49:24-31 
Improving Yield of Straw Mushroom Through Gamma Irradiation / Intl J Agric Biol, Vol 27, No 1, 2022

Rashid RA, F Daud, S Senafi, MR Awang, A Mohamad, HH Mutaat, MM Maskom (2014). Radiosensitivity study and radiation effects on morphology characterization of grey oyster mushroom Pleurotus sajor-caju. In: AIP Conference Proceedings, Vol. 1614, pp:570-574. American Institute of Physics, Maryland, USA

Rosmiza MZ, WP Davies, MJ Jabil, M Mazdi (2016). Prospects for increasing commercial mushroom production in Malaysia: Challenges and opportunities. Mediterr J Soc Sci 7:406-406

Rosnina AG, ST Yee, A Noorlidah, S Vikineswary (2016). Morphological and molecular characterization of yellow oyster mushroom, Pleurotus Citrinopileatus, hybrids obtained by interspecies mating. World J Microbiol Biotechnol 32:1-9
Shrivastava M (2006). Studies on radiation sensitivity of irradiated oyster mushroom spawn and shelf life of its sporophore. Master's Thesis. Jawaharl Nehru Krish Vishwa Vidyalaya, Jabalpur, India

Thiribhuvanamala G, S Krishnamoorthy, K Manoranjitham, V Praksasm, S Krishnan (2012). Improved techniques to enhance the yield of paddy straw mushroom (Volvariella volvacea) for commercial cultivation Afr J Biotechnol 11:12740-12748

Ukoima HN, LO Ogbonnaya, GE Arikpo, FN Ikpe (2009). Cultivation of mushroom (Volvariella volvacea) on various farm wastes in Obubra local government ofCross RiverState, Nigeria.Pak J Nutr 8:1059-1061

Xiong QL, ZT Xing, Z Feng, Q Tan, YB Bian (2009). Effect of 60 Co $\gamma$ irradiation on postharvest quality and selected enzyme activities of Pleurotus nebrodensis. Food Sci Technol 42:157-161 